Vol. 10 (1): 67-72 (2020)

\title{
FLOW OF TUBERCULOSIS BY AGE, GENDER AND CITIES DURING THE PERIOD 2003-2014 IN KOSOVO
}

\author{
Rukije Mehmeti $^{{ }^{*}}$, Hasan Hafizi ${ }^{2}$ \\ ${ }^{1 *}$ SHSKUK-Pulmological Clinic, Kosovo; \\ ${ }^{2}$ University Hospital "Shefqet Ndroqi", Faculty of Medicine, Tirana, Albania;
}

Correspondence author Rukije Mehmeti, email mehmeti_rukije@yahoo.com;

Received November 2019; Accepted December 2019; Published January 2020;

DOI: https://doi.org/10.31407/ijees10.109

\begin{abstract}
Tuberculosis is the ninth leading cause of deaths worldwide and is caused by a single infectious agent, Mycobacterium tuberculosis. This is a retrospective study followed during the years 2003-2014 in Kosovo. All TB patient treatment files throughout the Kosovo region were processed and all TB patients were included in the study. The study included 10669 patients disaggregated by years, and data were analyzed by gender, age and regions. Even though all age groups are at risk of tuberculosis, the prevalence is observed in the age group of 21-30 years with $22.2 \%$ of the total and age group $>60$ with $24.9 \%$ of the total, with significant statistical difference with other age groups $(\mathrm{p}<0.001)$. Therefore, tuberculosis in Kosovo is more prevalent in persons over 60 years, as in the developed European countries. Early diagnosis, contact processing and detection of TB cases on time will have a significant impact in reducing the TB cases.
\end{abstract}

Keywords: TB, diagnosis, trend, prevention 